\title{
A Evolução da Calça Jeans e do Comportamento do Consumidor: uma reflexão como parâmetro para a concepção do produto
}

\author{
The Evolution of Jeans and Consumer Behavior: a reflection as the yardstick for product \\ design.
}

\author{
ALMEIDA, Ariana de Camargo Villela Rocha. Especialista; \\ Universidade Estadual de Londrina; \\ arianavillela@gmail.com \\ EMIDIO, Lucimar De Fátima Bilmaia. Mestre; \\ Universidade Estadual De Londrina; \\ lucimaremidio@gmail.com.
}

\begin{abstract}
RESUMO
Considerando a demanda do produto calça jeans, que sofre diversas influências, entre elas, a moda urbana observada pelas pessoas durante seu dia a dia, este trabalho procura investigar por meio de pesquisa bibliográfica e de campo as expectativas e experiências de usuárias, em relação ao referido produto de vestuário de moda. Acredita-se que os resultados apresentados servirão como norteadores para o processo de desenvolvimento de novos produtos deste segmento, ao apontar aspectos de satisfação ou insatisfação, perante as características apresentadas, pelas usuárias investigadas.
\end{abstract}

Palavras-chave: Design de Moda, Ergonomia; Produto Calça Jeans.

\begin{abstract}
Considering the demand of the product jeans, that suffers amounts of influences, like the urban fashion observed by people during their daily lives, this paperwork investigates through literature research and field, experiences and expectations of users in relation to this product of fashion clothing. It is believed that these results will serve as guidelines for the development process of new products in this segment by pointing out aspects of satisfaction or dissatisfaction, given the characteristics presented by the users surveyed.
\end{abstract}

Key words: Fashion Design, Ergonomics; Product Jeans.

\section{INTRODUÇÃO}

A disputa acirrada por mercados entre economias globalizadas resultou na busca de novos conceitos de produção e estratégias no vestuário feminino. Para atender as necessidades das consumidoras, que hoje, não procuram somente por qualidade, mas também conforto, estética e usabilidade nos produtos de moda, as indústrias aprimoram cada vez mais o processo de desenvolvimento de produtos, aperfeiçoando-os com a introdução de novos procedimentos, materiais, equipamentos e ferramentas.

O projeto de vestuário tem suas especificidades relacionadas à estética do produto final, porém, um dos principais objetivos para o sucesso de seu desenvolvimento é o conforto corporal do usuário. Em cada etapa da elaboração de um produto deve-se ter a visão de todo o processo industrial que o cerca, levando em conta a complexidade de toda função, que tem como finalidade vestir o corpo. Para atingir estes objetivos, a utilização dos fatores ergonômicos, vão além da investigação da 
melhoria e organização do trabalho.

Neste contexto, objetiva-se visualizar alguns conceitos sobre as transformações do produto de moda calça jeans ao longo dos séculos, ressaltando a importância do design para o melhoramento das etapas de projeto. Aponta-se a importância da ergonomia para a adequação dos produtos ao usuário, considerando dados históricos, desde seu surgimento, até a evolução no mercado nacional e nos processos industriais.

É considerável também a importância de executar uma análise documental que permita visualizar o contexto histórico do referido produto, o cenário de sua confecção, seu sistema de produção e modelagens mais utilizadas no decorrer da história, já que esse produto tem força no mercado e atrai muitas consumidoras.

O interesse pela investigação do produto de moda calça jeans é motivado por sua importância histórica, onde gradualmente popularizou-se entre as diversas peças que compõem o vestuário masculino e feminino. Hoje, ela é peça fundamental de vestuário, considerada por muitos o uniforme do mundo, presente em todas as classes sociais, com diferentes modelagens e estilos. Desta forma, busca-se contribuir para seu sucesso de evoluçao, uma vez que aborda questões que interferem, positiva ou negativamente, na relação entre o produto e o usuário.

\section{Moda: a evolução do vestuário ao longo dos tempos}

A moda vem sofrendo transformações conceituais desde que se democratizou, seguindo o conceito da roupa pronta para vestir. A imposição de uma vestimenta formal, de acordo com os costumes da sociedade antiga, foi substituída gradualmente por uma pluralidade de estilos, onde cada consumidor assume a liberdade de ser. Segundo Pezzolo (2003), essa democratização surge de uma necessidade de mercado que leva as empresas a adotar um sistema de produção diversificado, procurando atender às necessidades dos consumidores, em suas diferentes formas; adequando-se às suas exigências e aos diferentes segmentos existentes.

A principal função da moda é vestir as pessoas. A importância de um desenvolvimento adequado das peças reflete o sucesso mercadológico no universo do vestuário. Para Feghali e Dwyer (2001, p.37): "A história da moda está inserida no próprio desenvolvimento da humanidade e, consequentemente, na evolução e mudança de costumes".

Por se tratar de algo tão próximo ao usuário, à moda reflete a história da humanidade, representando situações e realidades que condizem com as necessidades das pessoas em cada momento de suas vidas, e, em cada situação que a moda possa servir como espelho de sua personalidade e estilo. Segundo Palomino (2003, p.14) “moda é um sistema que acompanha o vestuário e o tempo, que integra o simples uso das roupas no dia-a-dia a um contexto maior, político, social, sociológico"

Para dominar o mercado da Moda, é necessário conhecer os movimentos culturais, as origens dos produtos, as novas tendências, além de resgatar a história, para compreendermos a atualidade. A maneira de se vestir muda conforme as atividades, o ambiente, as situações, as pessoas e o simbolismo que deseja transmitir ao usar um determinado estilo de roupa. Dentre os produtos de moda expostos no mercado, a calça jeans é o que mais se enquadra nesse perfil, pois, ela acompanha o usuário em diversas situações, e é um dos produtos de moda mais procurados, apresentando uma variedade de estilos e modelagens, como mostra o contexto a seguir.

\section{História da calça jeans: do apelo proletário à mercados com diferentes significados}

De uma roupa resistente criada apenas para suportar o trabalho nas minas de ouro do oeste americano, o jeans atravessa o século XX, como o tecido mais popular do mundo. Segundo Pezollo (2003), Levi Strauss, industrial teuto-americano, inventor da blue jeans (calça Levi's) e fundador da empresa Levi Strauss Co, em 1947 saiu da Baviera (atual Alemanha) rumo aos Estados Unidos disposto a conquistar fortuna. Inicialmente montou uma alfaiataria em Nova York, mas, durante a colonização do Oeste americano, empolgou-se com a "corrida do ouro" e decidiu ir para lá, onde ele vendia aos mineradores uma lona muito resistente para cobrir suas carruagens e barracas. Após observar o trabalho dos catadores de ouro notou que esses ficavam ajoelhados por muito tempo em solo rústico, e necessitavam de uma calça resistente para suportar tanto esforço. Logo teve a ideia de confeccionar 
A Evolução da Calça Jeans e do Comportamento do Consumidor: uma... para a concepção do produto

calças de trabalho com a lona que vendia. Nascia assim a nova marca de calças Levi's pants, que rapidamente passaram a ser usadas por cowboys que trabalhavam com o gado e também possuíam a necessidade de algo resistente para proteger e ter mais durabilidade.

Para Laver (2003), sua incorporação na moda urbana, se deu pelos jovens da época, sobretudo na Europa, onde o seu uso simbolizava o rompimento com as normas impostas por uma sociedade conservadora e a rejeição dos códigos estabelecidos, associando-se o traje a liberdade, flexibilidade e sedução. Os jeans também rebateram a lógica da hierarquia descendente, uma vez que, em vez de sua introdução no mercado ser aplicada nas classes superiores, ele atinge o estrelato começando por vestir as classes menos favorecidas. De acordo com alguns especialistas, o esclarecimento deste fenômeno está na capacidade de resistência e praticidade do tecido, que não precisa necessariamente ser passado a ferro, suja pouco, e, é esteticamente agradável. Por estas e outras razões, a calça jeans resiste ao logo dos tempos e os jovens passam a usá-la de diversas maneiras como forma e expressão. As peças ganham visuais mais puídos e desbotados, deixando entreabrir pequenas partes através de rasgos feitos propositalmente.

Pezzolo (2003) afirma que a introdução da calça jeans como parte do vestuário se dá nos anos 50, quando o fenômeno musical do rock and roll estoura com Elvis Presley, que vestia jeans. Naquela época, vários artistas consagrados começaram a aparecer vestindo jeans. James Dean e Marlon Brando se consagram como símbolos do filme "juventude transviada", que retrata os "delinquentes juvenis", influenciando os costumes de uma época marcada pela repressão, e atribuindo ao denim o toque final da sua eternidade.

O tipo de modelagem, mais utilizado nesse período, foi a cintura alta, perna com o corte reto e levemente largo, e o comprimento cigarrete (na altura do tornozelo). Para Laver (2003), a história do vestuário representa os anos 50, como o início de uma nova maneira de se vestir livremente. Dentre as principais características destacam-se os jeans escuros, t-shirts, suéteres e jaquetas de couro. Já para as garotas, as saias rodadas e as cigarretes eram peças curingas para dançar à vontade.

Na década seguinte, ainda sob influência do rock, surge nas telas dos cinemas outro filme onde os atores principais usam a calça jeans. Com o título de Easy Rider (Sem Destino), é um clássico que retrata a juventude dos anos 60 , refletindo as atitudes e as aspirações de uma geração inquieta e insatisfeita. No mesmo ano do lançamento desse filme, ocorre numa pacata cidade norte-americana o maior festival musical efetivado desde então, o Woodstock, esse grande evento reuniu quase um milhão de pessoas, e apresentou grandes ídolos do rock, tais como Jimi Hendrix, The Rolling Stones, Sky and The Family Stone, Swet and Tear e muitos outros artistas e bandas, tendo como visual predominante o jeans, que a partir de então ganhou cada vez mais espaço dentro da sociedade jovem daquela época. Laver (2003) diz que a modelagem da década é marcada pelas calças de cintura baixa e justa, um modelo bem parecido com as calças atuais, que levam o nome de skinny. Nesse momento surgiram as calças desbotadas e surradas, e até hoje, são vendidas com aspecto de usadas. No final da década, os jovens passaram a comprar suas calças em brechós, já rasgadas ou com famosos remendos. Na virada da década, as minicalças jeans com elástico na cintura, junto com as camisetas, passam a ser usadas até por crianças.

Os anos de 1970 apresentam, além da influência rock ainda existente, a influência hippie, que mudou completamente a maneira de pensar da sociedade, permitindo-os serem livres para tomar suas decisões até mesmo na maneira de se vestir. Segundo Laver (2003), as calças ganharam inovações em seus modelos aparecendo as pantalonas e as "bocas-de-sino", que foram um sucesso entre os jovens. Desde então, a cultura do jeans estava totalmente ligada a eles, porém, não demorou muito e as pessoas mais velhas começaram a aderir à moda jovem, e também passaram a usar a calça jeans, tornando-a uma peça universal. A partir disso, o jeans passou a ser confeccionado com várias opções de acabamento: sujo, manchado ou escrito, a fim de atender às diferentes tribos e classes de usuários.

De acordo com Pezzolo (2003), a década de 1980 é marcada pela moda prêt-à-porter. Um dos principais marcos deste momento foi o retorno da concepção do vestir-se bem, dos padrões sociais mais elevados e do resgate da elegância e classe ao se vestir. Essa época é marcada pelo surgimento de grandes marcas consagradas até hoje pela sua qualidade e design. A grande tendência mostrada nas passarelas era o preto, então, surgiram também o jeans Black, ao lado do tradicional blue. A modelagem 
adotada nesse período apresentava cintura alta, o famoso modelo baggy (com o quadril mais largo e perna afinalada). Começaram a ser introduzidas calças com fibra de elastano, e assim, a modelagem foi se ajustando ao longo da década, devido ao culto e valorização do corpo, e a influência do surgimento de academias de ginástica, além da influência pop e disco, que demonstravam ousadia.

Nos anos de 1990, novas tecnologias ampliam a gama dos tecidos sintéticos e criam os "tecidos inteligentes", tornando as roupas mais práticas e confortáveis. Segundo Pezzolo (2003), as mulheres começam a usar calças mais justas e a cintura, que no início era bem alta, vai abaixando aos poucos. As calças começam a marcar mais o corpo feminino. Este momento exibe o retorno das pantalonas $\mathrm{e}$ "bocas-de-sino", mas não por muito tempo, pois as mulheres já se preocupam mais com a sensualidade, preferindo peças mais justas. No final daquela década, entraram em moda os jeans stretch, presentes até hoje em grande parte do mercado.

Assim como nas décadas anteriores, o jeans assumiu no mercado diferentes significados, atendendo a todos os tipos de consumidores, que o adaptavam ao seu estilo de vida. Catoira (2006) afirma que as mulheres dos anos de 1990 apresentam um estilo de vida diferenciado, após sua conquista por liberdade. Elas são ao mesmo tempo dinâmicas, ativas, esportistas, trabalhadoras e sensuais. Elas aparecem no mercado de trabalho ao lado dos homens, batalhando e chefiando sua família e empresa, portanto, apresentam um ritmo cotidiano diferente, que faz com que a praticidade do jeans adaptese ao seu dia-a-dia. Este momento marca a volta do uso do elastano no jeans, proporcionando maior conforto às peças, e atribuindo sensualidade.

A realidade do mercado da calça jeans no século XXI, segundo Catoira (2006), apresenta marcas globais jeanswear que estabelecem o conceito premium jeans, que pode custar o preço de algumas jóias, atribuindo ao denin uma reputação que precede sua própria história. $O$ curioso é que a peça que nasceu com apelo proletário ganha status, e passa a ser até mesmo um artigo de luxo.

Considerando que este estudo é relacionado a uma peça do vestuário que estabelece uma relação íntima e permanente de contato táctil e visual com seu usuário, a preocupação com a qualidade ergonômica e o bem estar do indivíduo é fator imprescindível. Sendo assim, aborda-se a seguir a importância de se considerar os parâmetros ergonômicos na concepção dos produtos do vestuário, especialmente do produto calça jeans, objeto deste estudo.

Contribuições da ergonomia para o processo de concepção de produtos do vestuário

A ergonomia é um estudo que visa solucionar problemas em relação ao design, produto e usuário. Segundo Wisner (1987), a ergonomia se baseia em conhecimentos no campo das ciências relativas ao ser humano (ciência antropométrica, fisiologia, biomecânica, engenharia, psicologia, e parte da sociologia), com enfoque não apenas no ambiente de trabalho, mas na concepção de novos produtos, inclusive no vestuário que necessita de conhecimentos nas áreas citadas.

O suporte do produto industrial vestuário de moda é o corpo humano. Trata-se de uma estrutura tridimensional articulada, e em constante movimento. Para que o produto se torne satisfatório perante o consumidor em termos de qualidade, ele deverá reunir características adequadas ao perfil do público a que se destina, como conforto, funcionalidade e estética, percebidos antes e durante seu uso.

Os estudos ergonômicos contribuem com o auxílio na evolução e solução dos projetos de moda, qualificando o sistema de produção, ao questionar situações diárias do usuário. A ergonomia aplicada ao desenvolvimento de produtos tem seu foco na utilização, no aprendizado, na eficiência, na segurança e no conforto, objetivando atender os desejos e necessidades do ser humano.

Para, BAXTER (2003, p.178):

A palavra ergonomia é derivada do grego ergon, que significa trabalho e nomos, que significa regras. No princípio, a ergonomia estudava o homem no seu ambiente de trabalho, mas agora ela ampliou os objetivos, estuda as interações entre as pessoas e os artefatos em geral, e o seu meio ambiente.

Aplicar o estudo de processos ergonômicos a uma peça de vestuário deve atender aos diversos biotipos do público alvo, proporcionando acabamento adequado para que esses sintam 
liberdade ao se movimentar. O desenvolvimento de novos tecidos e padrões de modelagem buscam aperfeiçoar relações de conforto térmico e físico, influenciado por questões como transpiração, e diferenças climáticas.

A atividade projetual de um produto qualquer está centrada na satisfação e nas necessidades do usuário. Para Slack (1997), durante a aquisição de um produto, os clientes não estão somente comprando um produto ou serviço, mas um conjunto de benefícios esperados para atender suas expectativas. Portanto, as atividades exercidas durante um projeto de produto não são lineares, elas normalmente são marcadas por avanços e retornos, que possibilitam o aperfeiçoamento de diversas etapas. Baxter (2003) contribui para esta linha de pensamento ao declarar que uma decisão tomada em determinada etapa pode afetar a solução anteriormente adotada para melhorar o produto.

Considerando a importância de projetar produtos ergonômicos, Petrosky (1999) argumenta que a antropometria procura a determinação objetiva do desenvolvimento do corpo humano, abordando as relações existentes entre aspectos físicos e seu desempenho. Neste contexto, ressalta-se que os estudos antropométricos apresentam grande importância no desenvolvimento dos produtos de moda, principalmente em produtos utilizados com grande frequência, como a calça jeans.

Os diferentes parâmetros de influência na ergonomia de um produto de moda demonstram a complexidade que envolve o desenvolvimento de padrões de modelagens utilizados na indústria do vestuário, principalmente com relação ao produto aqui abordado, o qual atende a diversos tipos de consumidoras cada qual com um estilo ou padrão de modelagem.

O mercado hoje oferece muitas possibilidades às usuárias, porém, muitas vezes desconsidera questões que interferem na saúde, conforto e bem estar destas, ou seja, oferece produtos que dispõe de algum risco referente à saúde das mesmas, justifica-se, portanto, a importância da pesquisa, apresentada a seguir, por destacar elementos que servirão como norteadores para o desenvolvimento do referido produto.

\section{A ESTRUTURAÇÃO DA PESQUISA}

Pelos objetivos deste trabalho, optou-se por utilizar de estudos bibliográficos e exploratórios qualitativos visando, em primeiro plano, abordar o processo histórico-social de inserção da calça jeans na sociedade. De acordo com Mattar (1997, p.80), a pesquisa exploratória "visa prover o pesquisador de um maior conhecimento sobre o tema ou problema de pesquisa em perspectiva", levando em consideração que o tema abordado não possui informações conclusivas direcionadas, assim, essa a pesquisa contribui para a compreensão do mesmo.

A segunda fase da pesquisa é de natureza quantitativa, envolve o uso de técnicas de coleta de dados e instrumentos de pesquisa: questionário e observação sistemática (feita pelo entrevistador). Os procedimentos metodológicos adotados procuram levantar dados que identifiquem aspectos de motivação, uso, frequência, modelagem, preferências, saúde e conforto, baseados em entrevistas com usuárias de calça jeans, a fim de demonstrar a influência de diversos aspectos, abordados a seguir, para contribuição no âmbito da concepção do produto, que melhor satisfaça a usuária e consequentemente contribua no melhoramento mercadológico do mesmo. É uma pesquisa do tipo descritiva, que foi realizada com usuárias do sexo feminino, abrangendo diferentes perfis. Dividiu-se as entrevistadas em três grupos com diferentes idades, sendo: grupo 1: idade de 15 à 35 anos; grupo 2: de 36 à 56 anos e grupo 3: de 57 à 71 anos, objetivando descrever suas principais experiências, características e relações com o produto, em diversas situações de uso. Segundo Mattar (1997), a entrevista focalizada individual, tem algumas características, como: técnica pouco estruturada, aplicada por um entrevistador traquejado, e individual, e visa à coleta de informações sobre o assunto que está sendo analisado. Os resultados da pesquisa de campo elaborada são apresentados por gráficos que especificam a faixa etária das usuárias entrevistadas, e sua relação com o produto estudado, de acordo com as perguntas colocadas na Tabela 1, apresentadas no próximo item.

Utilizou-se também de imagens de apoio, sendo: Figura 1, relacionada a uma campanha publicitária e Figura 2, a imagem do perfil das usuárias entrevistadas, mostradas a seguir:

Figura 1: ilustração publicitária de José Luiz Benício para Levi's 


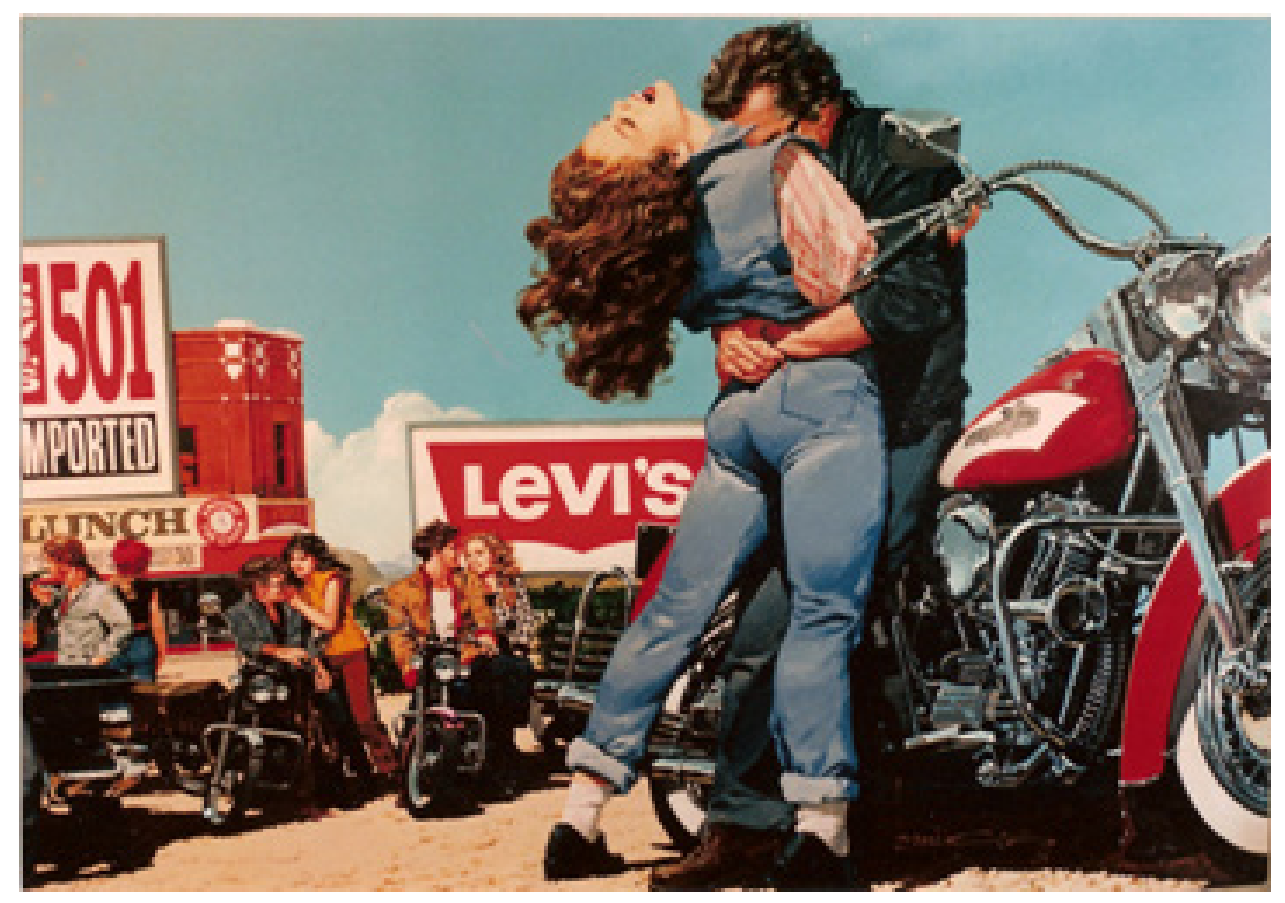

Figura 2: perfil das usuárias entrevistadas

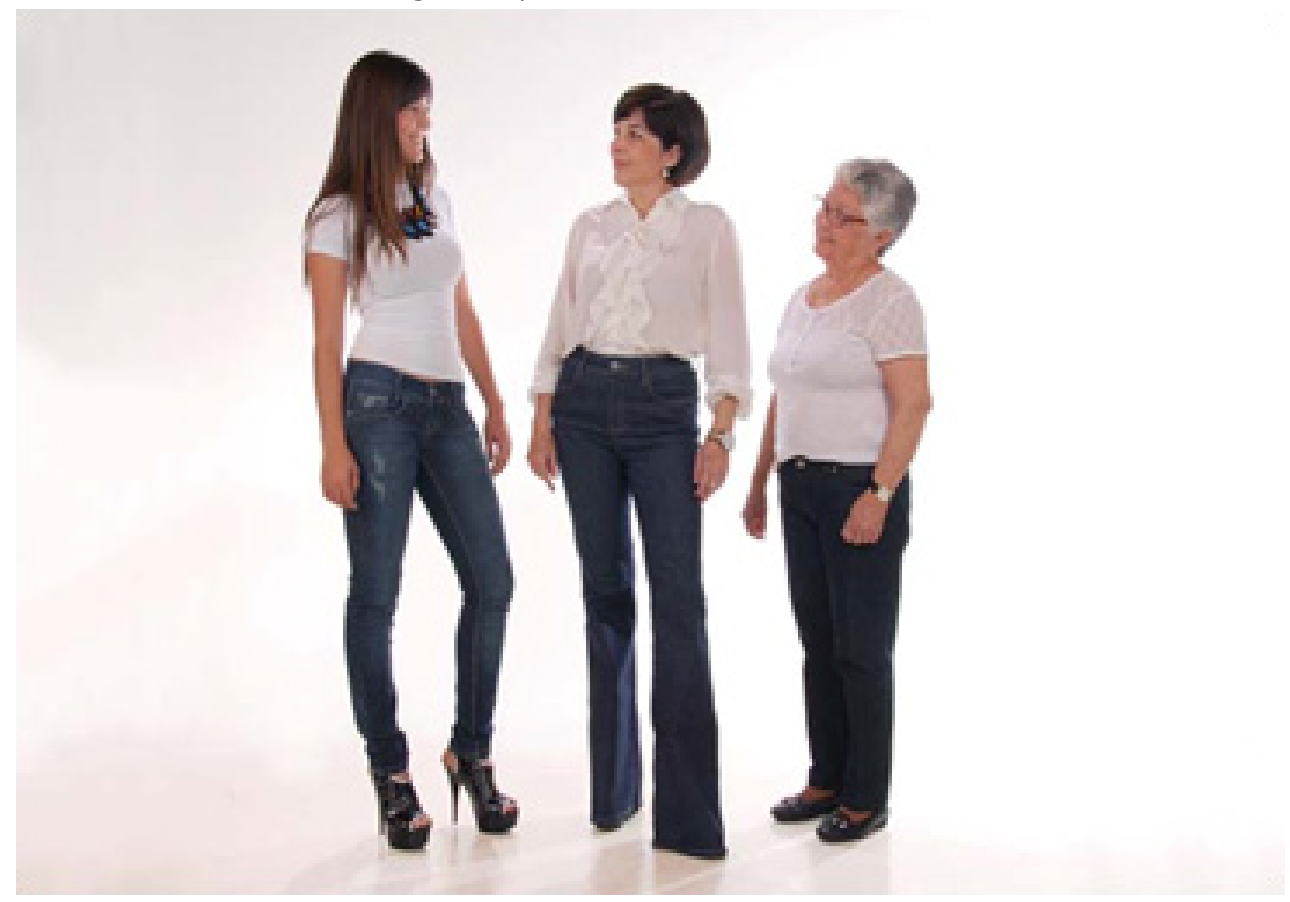

Optou-se por pesquisar mulheres bem distintas, com diferentes experiências em relação ao produto, e com ocupações variadas. O objetivo foi averiguar o quanto essas diferenças influenciam no consumo de calça jeans. Neste sentido, a pesquisa realizada procurou analisar as características de quem vai usar o produto, as situações a que se submetem durante seu uso, e sua satisfação com relação a ele, dividindo esse perfil de usuária em três grupos com idades bem diferenciadas, porque tais informações são de grande importância para a análise de dados e relevantes como parâmetros para o melhoramento do produto final.

Para o desenvolvimento de produtos do vestuário, além da investigação sobre a preferência dos consumidores, deve privilegiar suas opiniões. Existe diferença entre a reação de uma pessoa (consumidor) frente a um objeto que nunca viu e a reação da mesma pessoa após utilizá-lo (usuário), 
A Evolução da Calça Jeans e do Comportamento do Consumidor: uma... para a concepção do produto

principalmente quando se refere a peças do vestuário, que devem se adaptar à forma do corpo. 0 consumidor pode desejar um produto do vestuário, mas não pode ter a certeza de sua vestibilidade $e$ conforto antes de seu uso. Com base neste contexto, estruturou-se a pesquisa a partir de 10 questões chaves, mostradas no Quadro 1, a seguir:

Quadro 1: escopo da pesquisa de campo.

\begin{tabular}{|c|c|c|}
\hline QUESTOEES & PERGUNTAS & OBJETIVO \\
\hline 01 & $\begin{array}{l}\text { Com que frequếncia utiliza a } \\
\text { calça jeans? }\end{array}$ & $\begin{array}{l}\text { O objetivo da primeira pergunta do questionário foi descobrir se as } \\
\text { mulheres ainda usam a calça jeans no seu dia a dia, e com que } \\
\text { frequência usa, pois, devemos ter conviç̧ăo de que esse produto } \\
\text { está presente no vestuário feminino e de que forma ele se impóe. }\end{array}$ \\
\hline 02 & $\begin{array}{l}\text { Em quais situaçóes vocé mais } \\
\text { utiliza a calça jeans? }\end{array}$ & $\begin{array}{l}\text { Essa queståovisou averiguar quais såo as situaçôes cotidianas que as } \\
\text { usuárias mais utilizam a calça jeans. Considerou-se importante para } \\
\text { a pesquisa, perceber em quais ambientes as mulheres preferem usar } \\
\text { esse produto, pois, cada um deles, pede uma postura diferente, no } \\
\text { que diz respeito a estilo, modelagem e lavagem. }\end{array}$ \\
\hline 03 & $\begin{array}{l}\text { Vocé considera a calça jeans uma } \\
\text { peça confortável? }\end{array}$ & $\begin{array}{l}\text { Ao longo dos tempos, a calça jears, sofreu diversas muctanças. A } \\
\text { modelagem a cada temporada ganha um novo estilo. A propriedade } \\
\text { têxtil novas performances e tramas, e a evoluçào das lavagens } \\
\text { colabora cade dia mais para evoluçào desse produto. Neste } \\
\text { contexto, as questốes de relacionamento entre usuário e produto, } \\
\text { investigou se suas usuárias a consideram confortáveis ou nào. }\end{array}$ \\
\hline 04 & $\begin{array}{l}\text { Já viveu algum momento de } \\
\text { desconforto ao utilizar esta peça? } \\
\text { Caso a resposta sej sim, } \\
\text { descreva-o. }\end{array}$ & $\begin{array}{l}\text { Esse questionamento teve a finalidade de descobrir se as usuárias já } \\
\text { viveram algum momento de desconforto durante a utilizaçào do } \\
\text { produto. E em caso positivo, deu-se a oportunidade de escrever } \\
\text { quais problemas foram esses. }\end{array}$ \\
\hline 05 & $\begin{array}{l}\text { Que aspectos julga mais } \\
\text { importante ao optar pela calça } \\
\text { jeans ao se vestir? }\end{array}$ & $\begin{array}{l}\text { Essa questáo teve como objetivo, descobrir os aspectos que as } \\
\text { usuárias consideram mais importantes ao optar pela calça jeans ao } \\
\text { se vestir. }\end{array}$ \\
\hline $\begin{array}{c}06 \\
\text { [perg aberta ] }\end{array}$ & $\begin{array}{l}\text { Escolha as caracteristicas } \\
\text { preferidas para a modelagem do } \\
\text { seu jeans: }\end{array}$ & $\begin{array}{l}\text { Essa questáo teve como principal foco a modelagem, buscando } \\
\text { compreender quais sảo os modelos de calça jeans existentes na } \\
\text { história do produto que săo preferidos pelas mulheres. }\end{array}$ \\
\hline 07 & $\begin{array}{l}\text { Suas preferéncas para a } \\
\text { modelagem do jeans baseam-se } \\
\text { em que parâmetros? }\end{array}$ & $\begin{array}{l}\text { Tevese aqui o objetivo de analisar quais as preferéncias das usuárias } \\
\text { ao escolher a modelagem da sua calça jears, e quais aspectos se } \\
\text { tornam mais importantes no momento da escolha. A modelagem da } \\
\text { calça é um fator de extrema importância para a valorizaçăo do } \\
\text { biotipo, sensualidade, confớto e tendência de moda. Ela } \\
\text { proporciona uma diferenciação de modelos, e uma diversificação de } \\
\text { estilos. }\end{array}$ \\
\hline$O B$ & $\begin{array}{l}\text { Vocé possui conhecimento } \\
\text { quanto aos diferentes tipos de } \\
\text { tecido jeans, e leva isso em } \\
\text { considereção na hora da compra. }\end{array}$ & $\begin{array}{l}\text { Com este tipo de questắ buscou-se analisar se a usuária tem } \\
\text { conhecimento quanto aos diferentes tipos de tecidos jeans e quais } \\
\text { fatores se tornam mais importantes ao escolher determinadas } \\
\text { peças. }\end{array}$ \\
\hline 09 & $\begin{array}{l}\text { Vocé já ouviu falar em algum } \\
\text { problema provocado pelo uso } \\
\text { excessivo do jeans? }\end{array}$ & $\begin{array}{l}\text { É de grande importáncia saber se as usuárias já ouviram falar ou } \\
\text { eståo conscientes de que a calça jears usada excessivamente possa } \\
\text { causar algum problema. Esse questionamento permite identificar se } \\
\text { ele é percebido ou não ou se a evoluçâo das modelagens a } \\
\text { comprometeu fisicamente de alguma forma. }\end{array}$ \\
\hline 10 & 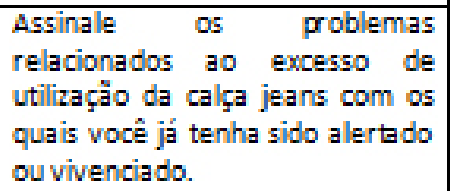 & $\begin{array}{l}\text { Essa queståo teve como objetivo, levantar dados em relaçåo aos } \\
\text { problemas vivenciados ou percebidos pelos grupos de entrevistadas } \\
\text { ao utilizarem a calça jeans com frequência. }\end{array}$ \\
\hline
\end{tabular}


ALMEIDA, Ariana de Camargo Villela Rocha; EMIDIO, Lucimar De Fátima Bilmaia

Análise e discussão dos resultados

Quadro 2: resultados da pesquisa de campo.

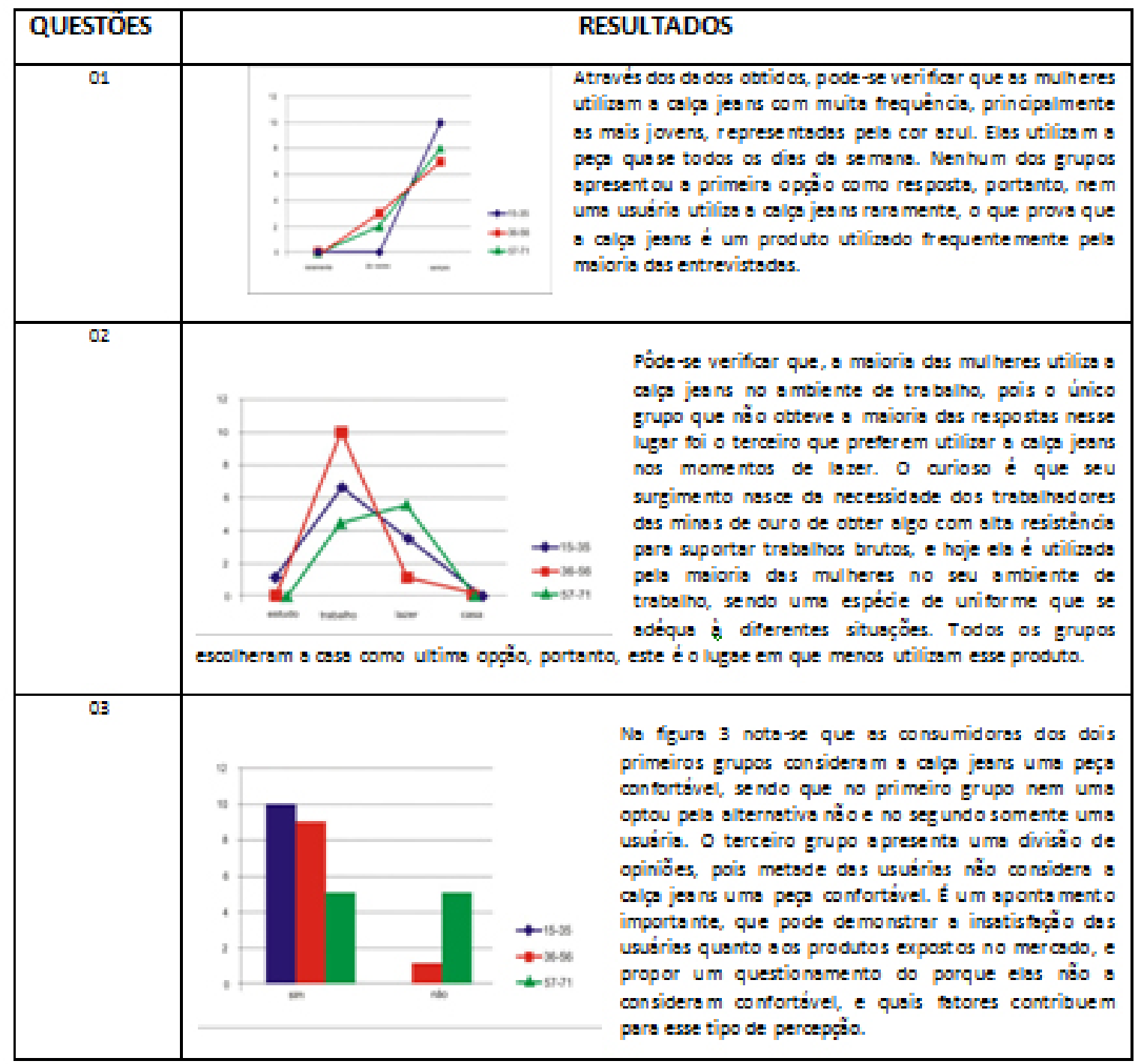

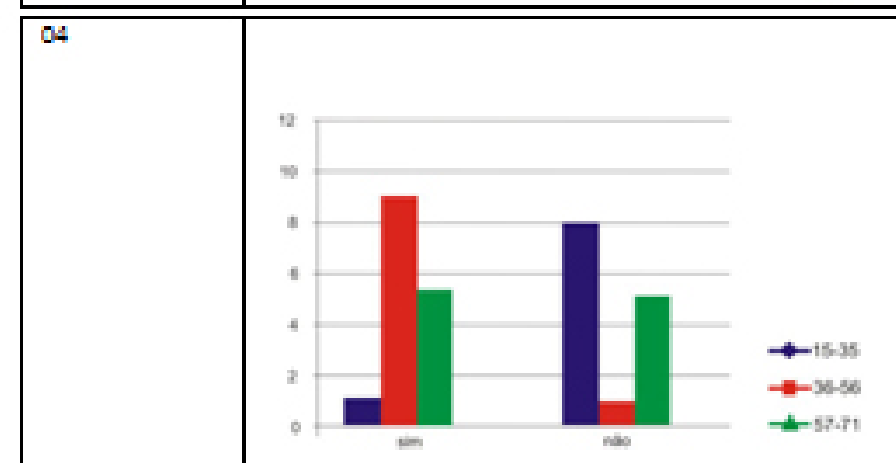

A andise de fgurs 4 permite verificar que o grupo que mais sotreu momentos de desconforto ne utilizeção desse produt o foi o 2 , que é representedo peies mulheres de 35 ì 95 anos, seus principais a po ntame ntos em rela çào a esse senseço de desconforto sio: o uso da calca jes ns em dias muito quentes; a taita de mobilidede em certos movimentos, (co mo so sentar-se); $O$ uso de modelagens com genchos muito beixos; $e$ o desconforto que a calga jeans muito juste spresenta spós as refeiçōes. As usuáries do primeiro grupo nào a presentaram

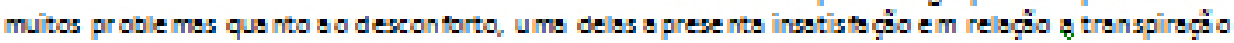
excessive em diss quentes, e a outre que disse que a calga ja "ma chucou". No terceiro grupo podere observer ume divisio de opiniǒes, pois, einco entrevistades responderam sim, e cinco responderem nĩo, es que vivenciarem esse momento de desconforto desereveram os seguintes problemes: modelagens justes, calor excessivo, transpirs çầ eleveds, e desconforto spós as refeiçỏes. Esss questĩo nos permitiu visualizar que apesar de maioria des mulheres acreditarem que o jeans é uma peça confortível, muites deles, sendo quese a maioria, spontam problemes que vivenciaram durante a sus utilinsậà 
Os elementos abordados neste estudo identificam que grande parte das entrevistadas utiliza

a calça jeans com muita frequência, quase todos os dias da semana. As situações em que elas mais utilizam a peça é no momento do trabalho, a minoria apontou a casa como preferência. $A$ maior parte das entrevistadas consideram a calça jeans uma peça confortável, exceto o grupo 3 que apresenta boa parte das respostas na opção não.

Ao questionar sobre os momentos de desconforto vivenciados pelo uso, o grupo que maior aponta esse problema na utilização do produto foi o 2, representado pelas mulheres de 36 à 56 anos, seus principais apontamentos em relação a essa sensação de desconforto são: o uso da calça jeans em dias muito quentes; a falta de mobilidade em quanto a certos movimentos, como ao sentarse; o uso de modelagens com ganchos muito baixos; e o desconforto que a calça jeans muito justa apresenta após as refeições, se ajustando demais ao abdomen. As usuárias do primeiro grupo (de 15 à 35 anos) não apresentaram muitos problemas de desconforto, somente duas entrevistadas apontaram problemas, uma em relação à transpiração excessiva em dias quentes, e a outra que disse que a calça já "machucou".

No terceiro grupo, representado por mulheres com idade de 57 à 71 anos pode-se observar uma divisão de opiniões, pois, cinco entrevistadas responderam sim, e cinco responderam não, as que vivenciaram esse momento de desconforto descreveram os seguintes problemas: modelagens justas, calor excessivo, transpiração elevada, e desconforto após as refeições. Para a maioria das mulheres o aspecto mais importante na hora da escolha do jeans para se vestir, é por ele ser uma peça-chave, fácil de combinar. A opção conforto não apresentou grande importância para elas.

Quanto as modelagens preferidas das usuárias, o grupo 1 e 2 preferem as calças de cintura baixa, e perna e barra levemente larga, o grupo 3 prefere modelagens de cintura média e alta, com a perna levemente justa. O que aponta uma diferença de preferências que devem ser analisadas para a busca dos aperfeiçoamentos na concepção do produto. A maioria das usuárias escolhe o tipo de modelagem pela valorização do seu biotipo, e geralmente tomam a decisão da escolha na hora da compra.

Um dos pontos mais importantes detectados na pesquisa foi a percepção da usuária quanto aos problemas relacionados ao excesso de uso do produto, pois, a maioria das entrevistadas sendo nove de cada grupo, num total de vinte e sete, disseram que reconhecem esse problema, sendo os mais citados a deformação física da cintura; o encravamento de pelos e a transpiração excessiva. Esses problemas apresentados pelas usuárias demonstram a importância das pesquisas relacionadas a esse tipo de produto.

\section{CONSIDERAÇÕEAS FINAIS}

Ao projetar um produto de moda deve-se levar em consideração, as características do público a que se destina, que abrangem variáveis como: idade, sexo, raças, etnias, tipo de atividade em que mais utiliza-o, entre outros. O projeto de vestuário está diretamente relacionado a estética do produto, porém, o principal objetivo a ser alcançado durante o seu desenvolvimento é a vestibilidade e a satisfação do usuário. Nesse sentido, o desafio das empresas é elaborar artigos de vestuário altamente orientados para o mercado. Eles devem compreender aspectos estéticos, simbólicos e as funções que visam o conforto fisiológico do corpo.

Neste contexto os resultados deste trabalho mostram o quanto é decisivo para o processo de concepção de produto, definir as características de quem vai usá-lo uma vez que a padronização das medidas nem sempre apresentam parâmetros suficientes de conforto, eficiência e segurança do produto para o usuário.

Por ser um tema pouco explorado, notou-se que há a necessidade de novas abordagens metodológicas, mais detalhadas e específicas, contemplando outros tipos de usuários, buscando informações em diversas áreas do conhecimento, que tratam das necessidades físicas e psicológicas do consumidor. Espera-se que a reflexão aqui apresentada possa contribuir como norteadora de projetos industriais do vestuário calça jeans, que garantam ao usuário uma maior satisfação ao vestir. 


\section{REFERÊNCIAS}

BAXTER, M. Projeto de Produto: guia prático para desenvolvimento de novos produtos. São Paulo: Ecgard Blücher, 1998.

BRIDGER, R. S. Introduction to ergonomics. Singapore: Mcgrau - Hill International Editions, 1995. CATOIRA, Lu. Jeans, a roupa que transcende a moda. Aparecida, SP: Idéias \& Letras, 2006.

CHEVALIER, Jean; GHEERBRANT, Alain. Dicionário de símbolos: mitos, sonhos, costumes, gestos, formas, figuras e números. Tradução: Vera da Costa e Silva [et al.]. 15. ed. Rio de Janeiro: José Olympo, 2000.

DWYER E FEGHALI, Daniela e Marta Kasznar. "As Engrenagens da moda". Rio de Janeiro. Ed. Senac Rio, 2004.

HOLLANDER, Anne. O sexo e as roupas: a evolução do traje moderno. Rio de Janeiro: Rocco, 1996.

IIDA, I.. Ergonomia: projeto e produção. São Paulo: Edgard Blücher, 2001.

IIDA, Itiro. Ergonomia, projeto e produção. 7ed. São Paulo: Edgard blucher Itda, 1990.Janeiro: Edgard Blücher, 2000

LAVER, James, A roupa e a moda. 7ed. São Paulo: Companhia das letras, 2003.

LÖBACH, B. Desenho Industrial: bases para configuração dos produtos industriais. Rio de Janeiro: Edgard Blücher, 2001. LÖBACH, B. Desenho Industrial: bases para configuração dos produtos industriais. Rio de

MATTAR, Fauze Najib. Pesquisa de marketing: metodologia, planejamento. 4ed. São Paulo: Atlas, 1997.

PALOMINO, Érika. "A moda”. 2 ed. São Paulo: Publifolha, 2003.

PETROSKI, E. L. Antropometria: técnicas e padronizações. Porto Alegre: Palotti, 1999.

PEZZOLO, Dinah Bueno. Moda Fácil. São Paulo: códex, 2003.

RECH, Sandra Regina. Moda: por um fio de qualidade. Florianópolis- SC. Editora da UDESC, 2002.

SILVEIRA, I. Análise da Implantação do sistema CAD na indústria do vestuário. In: Moda palavra. Florianópolis: UDESC/CEART, 2003, v. 3, p. 17-30.

SLACK, N. et. al. Administração da Produção. São Paulo: Atenas, 1997.

WISNER, Alain. Por dentro do trabalho: ergonomia: método e técnica. Tradução Flora Maria Gomide Vezzá. São Pauloç FTd: Oboré, 1987.

ROUSSEAU, Rene Lucien. A Linguagem das cores: energia, simbolismo, vibrações e ciclos das estruturas coloridas. São Paulo: Pensamento, 1980.

SAMARA, Beatriz Santos; BARROS, José Carlos de. Pesquisa de Marketing: Conceitos e Metodologia. 3. ed. São Paulo: Atlas, 2001.

SEMPRINI, Andrea. A Marca pós moderna: Poder e fragilidade da marca na sociedade contemporânea. São Paulo: Estação das letras, 2006.

VILLAÇA, Nizia. Mixologias: Comunicação e o consumo da cultura. São Paulo: Estação das letras e 
A Evolução da Calça Jeans e do Comportamento do Consumidor: uma... para a concepção do produto Cores, 2010. 